\title{
Os procedimentos de escrita de José Cardoso Pires ${ }^{1}$
}

\author{
IZABel Margato \\ Pontifícia Universidade Católica do Rio de Janeiro
}

RESUMO: A OBRA DE JOSÉ CARDOSO PIRES PARECE PROPOR O DISCURSO LITERÁRIO COMO RELATO ALTERNATIVO AO DISCURSO OFICIAL, AQUELE PRODUZIDO PELO ESTADO PARA ESTABELECER CONSENSOS E FIXAR A SUA VERSÃO DOS FATOS. NESTE TRABALHO, A AUTORA BUSCA DESVELAR OS PROCEDIMENTOS DE ESCRITA MAIS EVIDENTES DA OBRA DE CARDOSO PIRES, QUE CONSTITUEM, SEGUNDO ELA, UM MOVIMENTO INTERROGATIVO QUE FAZ DE SUA ESCRITA UMA ESPÉCIE DE "PROVA", A PARTIR DA QUAL SÃO AFERIDAS AS INTERPRETAÇÕES CONSAGRADAS PELO USO OU PELAS POLÍTICAS DE CONSENSO.

ABSTRACT: JOSÉ CARDOSO PIRES'S WORKS SEEM TO PROPOSE THE LITERARY TEXT AS AN ALTERNATIVE ACCOUNT TO THE OFFICIAL DISCOURSE, THAT ONE CREATED BY THE STATE TO ESTABLISH CONSENSUS AND TO FIX ITS VERSION OF THE FACTS. IN THIS ARTICLE, THE AUTHOR AIMS TO REVEAL CARDOSO PIRES' MOST EVIDENT WRITING PROCEDURES, WHICH CONSTITUTE, ACCORDING TO HER, AN INTERROGATIVE MOVEMENT THAT MAKES OF HIS WRITING A KIND OF "PROOF" THROUGH WHICH THE INTERPRETATIONS ACCEPTED BY THE USE OR BY THE CONSENSUAL POLITICS ARE PUT INTO TEST.

PALAVRAS-CHAVE: JOSÉ CARDOSO PIRES - LITERATURA PORTUGUESA CONTEMPORÂNEA - LITERATURA E HISTÓRIA - LITERATURA E POLITICA KEY-WORDS: JOSÉ CARDOSO PIRES - CONTEMPORARY PORTUGUESE LITERATURE LITERATURE AND HISTORY - LITERATURE AND POLITICS

\footnotetext{
${ }^{1}$ Este texto é um dos resultados da pesquisa que venho desenvolvendo com o apoio do CNPq.
} 
uem escreve está a estabelecer uma discussão com alguém.

José Cardoso Pires

A escrita constitui uma prova e como que uma pedra de toque: ao trazer à luz os movimentos do pensamento, dissipa a sombra anterior onde se tecem as

tramas do inimigo.

Michel Foucault

Interrogar e discutir são os procedimentos de escrita mais evidentes dos textos de José Cardoso Pires. Em cada um deles, percebemos um ponto de vista em movimento, um movimento que interroga, desgasta, afia e vai até o osso dos fatos, para trazer à luz os "movimentos do pensamento" que fazem de sua escrita uma espécie de "prova", ou de "pedra de toque" a partir da qual são aferidas as interpretações consagradas pelo uso ou pelas políticas de consenso. Esses procedimentos dão forma ao que se convencionou chamar "escrita interrogativa", essa marca em relevo que define uma posição e, mais precisamente, uma tomada de posição diante de acontecimentos e de suas interpretações. Em entrevista a Artur Portela, esse "autovigiadíssimo prosador", ao ser perguntado se a sua posição resultava de ceticismo, ou derrotismo, responde sem hesitação: "Cepticismo, cepticismo. O derrotismo assenta na negação, e duvidar é um apelo à revisão, um princípio de análise" (CARDOSO PIRES, 1991: 84).

A postura que incita à revisão, que faz da escrita um procedimento de análise - já presente nos primeiros textos do autor -, cria uma relação tensa entre dois tipos de narrativa: as produzidas pelo Estado para estabelecer consensos e fixar a sua versão dos fatos, e as da literatura, com seus relatos alternativos, que enfrentam e analisam o funcionamento do relato estatal, pondo em causa a sua "máquina de fazer crer" (PIGLIA, 2001a).

Esse procedimento narrativo pressupõe a existência de uma verdade histórica que o escritor vai lutar para descobrir, sabendo de partida que ela só pode ser pressentida a partir de um movimento de luta e de confrontação (FOUCAULT, 1994). Nesse sentido, a noção de verdade que se depreende dos textos do autor vai ser entrevista antes de tudo como o resultado de um longo compromisso - o seu propósito rigoroso de comprometimento cívico - e de uma "guerra de relatos" (CERTEAU, 1996), em que ficam evidentes as escolhas da margem e da 
fidelidade ética como posicionamentos a partir dos quais são aferidos os "efeitos de realidade" (LYOTARD, 1999) produzidos pela ordem estabelecida. Ter "a noção de verdade como horizonte político e objeto de luta" (PIGLIA, 2001a) é, portanto, um valor a ser perseguido quando se pretende uma outra percepção da realidade. Ao longo de sua obra, Cardoso Pires fez desse valor cognitivo uma postura de vida, a que articulou, como num pacto, o seu procedimento de escrita.

Outro tópico que destacamos, no intuito de mapear alguns dos traços do cerimonial de escrita de José Cardoso Pires, é a focalização indireta e oblíqua com que o escritor lê os acontecimentos. Partindo da apresentação de um pequeno detalhe, um pormenor, a narrativa de Cardoso Pires convoca os diferentes sentidos com que esse objeto é tratado para, num movimento circular, desgastá-los e confrontá-los com uma nova percepção, diferente e específica. Curiosamente, esse sentido específico e particular não substitui nem exclui a percepção anterior, antes dá a ela uma outra funcionalidade: a de indiciar, na qualidade de cifra, uma certa forma de explicar a rede complexa que delimita e articula o nosso cotidiano. Trata-se de um procedimento que põe em questão os mecanismos oficiais com que se formam as visões de mundo, isto é, um tipo de percepção que não pode ser descartado, antes devendo ser analisado como mais um dado de uma construção interpretativa. Mais curioso ainda é a forma elíptica com que o escritor fixa esses conteúdos. Partindo do pressuposto de que é impossível expressar diretamente uma verdade entrevista, Cardoso Pires narra como alguém que busca um objeto que nunca será explicitamente nomeado. Para proceder a essa modalidade de escrita, o escritor trabalha com duas lógicas narrativas diferentes: uma que investiga e analisa de forma cerrada o objeto ou o fato em questão e uma outra que, através da elipse e da condensação, vai pontuando um sentido subterrâneo - como um subtexto - que nunca se deixa ver completamente. Narrar um fato como se estivesse falando de outro e dizer o máximo de forma mais contida e com a menor quantidade de palavras (PIGLIA, 2001a) é mais um procedimento que se destaca na escrita de José Cardoso Pires. A esse procedimento articula-se a incitação ao leitor ideal, ou, melhor dizendo, articula-se uma provocação, um apelo à suspeita e à discussão.

"[...] prefiro, em literatura, pecar por defeito a pecar por excesso. Prefiro dizer de menos do que dizer de mais, porque, se digo de mais, mato o leitor, o leitor apaga-se. Apaga-se a sua suspeita" (CARDOSO PIRES, 1996). 
Poderíamos dizer que esse apelo nasce de um profundo respeito pelo outro e de uma concepção de escrita que inclui, e ao mesmo tempo convoca, os próprios mecanismos de leitura. A construção narrativa a duas vožes, aliada aos recursos de condensação e elipse, suscita uma prática de leitura em permanente movimento de suspeição, interrogação e análise. Com esse procedimento - de leitura difícil - o leitor é "ferido de morte", não como alguém que se apaga ou que apenas recebe soluções prontas para as verdades previamente intuídas, mas como alguém que, uma vez ferido, cresce a cada passo da leitura e se transforma, ele também, em mais um leitor crítico - uma espécie de detetive - que interroga e investiga os mecanismos com que são tecidas as "verdades do mundo".

A construção narrativa oblíqua e condensada vai produzir um tipo de subtexto que tem no iceberg o seu modelo emblemático. Essa alegoria é também um traço bastante conhecido e comumente atribuído à escrita de Cardoso Pires. Entretanto, é importante destacar que esses procedimentos aqui apresentados só adquirem verdadeiramente sentido quando percebemos que o projeto de criação literária do autor só pode ser pensado como um processo articulado às questões sociais e políticas do seu tempo e, fundamentalmente, do seu país. Com isso não estamos negando o universo mais amplo a que a sua obra remete; antes chamamos a atenção para a urgência do fato de Cardoso Pires ter nascido em 1925 e de ter, portanto, vivido os quase cinqüenta anos de um regime ditatorial, violento e conservador. A sua obra nasce, conseqüentemente, de um profundo sentimento de responsabilidade cívica que se evidencia claramente na recusa e na interpelação que faz às políticas do Estado Novo Português. Enfrentando as diferentes expressões da censura inquisitorial, Cardoso Pires promove com seus textos um contínuo movimento de barragem e de acareação às ficções estatais com que a ditadura se manteve por tanto tempo no poder. Esses procedimentos trazem à luz um pensamento crítico que busca clarificar o espaço de "sombra" em que eram tecidas "as tramas do inimigo", isto é, as suas soluções compensatórias, os relatos de conteúdos didáticos das notas de todo dia e, invariavelmente, os enredos de proveito e exemplo das suas histórias de terror. Como narrar a experiência de terror que o fascismo veicula e espalha como uma epidemia? Como narrar o horror de todos os dias de uma experiência de quase cinqüenta anos? Talvez possamos arriscar uma resposta - mesmo que seja na condição de hipótese - a essa 
indagação com que Cardoso Pires se fez acompanhar ao longo da vida: o terror - como toda verdade - deve ser apenas entrevisto, aludido e condensado numa imagem forte para que salte do relato, como uma seta, e nos transpasse e fira, para depois ficar ecoando, resistente, como uma cicatriz. Uma outra possibilidade que a obra do autor indicia como resposta a essa demanda é a que se constrói com o recurso do deslocamento. Trata-se, de certo modo, de uma variação do tópico acima apresentado como um procedimento sutil, marcado pelas figuras de condensação e elipse. Trata-se também da alusão a uma verdade implícita, agora insinuada por uma troca pronominal; um movimento que desloca a enunciação para a voz de um outro e, da mesma forma que o procedimento anterior, obedece a uma lógica narrativa que vai além dos conteúdos focalizados no relato mais evidente. Esse procedimento de escrita tem sido analisado por Ricardo Piglia (2001b), como um recorte que quebra a seqüência narrativa para incorporar uma voz deslocada, elíptica, que é capaz de dizer e "mostrar o que não se pode dizer", funcionando, ao mesmo tempo, como um condensador de experiência. O deslocamento produz um movimento no relato até uma situação concreta, "onde há um outro que permite fixar e tornar visível o que se quer dizer”. Essa forma narrativa que faz lembrar a hipálage acentua o movimento indireto com que Cardoso Pires incita à interrogação. Logo nos seus primeiros textos, percebemos que a condensação, a alusão e o deslocamento funcionam como procedimentos de uma ficção destinada a "estabelecer onde está a verdade, a descobrir o segredo que o Estado manipula e a revelar o seu sentido escamoteado" (PIGLIA, 2001b). Esses procedimentos fazem lembrar os passos de investigação das narrativas policiais. É evidente que a escrita de José Cardoso Pires convoca esse modelo de ação. Convoca e reinscreve para dar a ele uma nova funcionalidade, pois é evidente que o escritor não compactua com as soluções compensatórias, ativadas pelas narrativas policiais. Em relação a esse tópico, ganha relevo o comentário do escritor em "Memória descritiva", texto "ensaístico" em que analisa o processo de desmistificação empreendido pelo "narrador furão" em seu romance O Delfim:

Desmistificar, portanto. Para isso está o meu Narrador metido na pele dum Maigret-Sherlock de fim de semana. E eu, por cima do ombro vou-o acompanhando na escrita, vendo-o entranhar-se no discurso, correr atrás de vozes, farejar indícios, à procura da autêntica face da Gafeira, ele que, coitado, nunca 
na vida foi grande apreciador de dramas policiais. Também eu não, confesso. Intrigas de dectetive deixam-me na calma. Tirando o caso raríssimo dum Dashiell Hammett e pouco mais, o que essa literatura faz é defender a propriedade burguesa e todas as instituições (polícias, seguros ou espionagens) que a garantam por muitos anos e bons. Só que goste ou não goste, acredite ou não nos mestres do crime e da dedução, o Narrador foi posto, logo ao abrir do romance, diante de uma culminação (a morte). A partir daí só lhe resta aprender a pegar na lupa e meter por uma fórmula lúdica de contar onde as imagens são gradativamente pervertidas até deixarem à vista certos traços do real. (CARDOSO PIRES, 1977b: 187)²

Embora concordemos com o autor que os seus textos se aproximam muito mais do "romance enigmático"3, já se tornou um lugar-comum evidenciar o diálogo que eles estabelecem com as formas consagradas da narrativa policial. Num comentário recente sobre Cardoso Pires, Eduardo Lourenço fez a seguinte afirmação:

Homem, nem de certezas nem de incertezas, nem olímpico nem angustiado, o autor de O Delfim investiu-se, como uma espécie de predestinação, no papel de detetive por conta própria, apostando na descoberta de enigmas ou crimes, secularmente sepultados, sob o espesso silêncio português, raiz e matriz do tempo sonâmbulo (a frase é dele) que lhe coube viver. Viver e reviver em contos e romances inseparavelmente realistas e alegóricos, onde em quem os

\footnotetext{
${ }^{2}$ Além desse posicionamento do autor, vale a pena recordar o ponto de vista que o escritor atribui ao personagem "Narrador Furão" no romance O Delfim: "a literatura policial é um tranqüilizante do cidadão instalado. Toda ela tende a demonstrar que não há crime perfeito.” [...] Tomás Manuel põe em dúvida [...] "Deve ter havido milhões de crimes altamente compensadores." "Está bem, mas não vêm nos romances. O Burguês pacato precisa de acreditar nas instituições. Mostrar-lhe que pode haver crimes perfeitos é o fim.” (CARDOSO PIRES, 1968: 248-9)

${ }^{3}$ De acordo com Cardoso Pires, "Pegando - com intenção - em Pierre Macherey, "O romance enigmático pelo menos tal qual é praticado por A. Radcliffe, parece portanto ser produzido pelo encontro de dois movimentos: um que institui o mistério, enquanto o outro o dissipa. Toda a ambigüidade da narração provém do facto de estes dois movimentos não se sucederem um ao outro (pois nesse caso só se anulariam no fim), mas de se acompanharem inextricavelmente, cada um (mas qual?) contestando indefinidamente o outro. Confere. A Cartada é a mesma dO Delfim" (CARDOSO PIRES, 1977b: 173).
} 
ler respirará um pouco aquele ar rarefeito de um passado português que foi o da sua geração e, eminentemente, o seu. (LOURENÇO, 1998)

O papel de "detetive por conta própria" de que fala Eduardo Lourenço poderia ser visto como um posicionamento do escritor, para investigar - como um profissional habilitado ao desvendamento de crimes - o tempo difícil, ou o tempo sonâmbulo, que lhe foi dado viver. Para melhor exercer essa prática de detetive "por conta própria" é necessário atualizar movimentos furtivos, recolher as pistas e examiná-las em segredo. É necessário escolher um "posto de observação", um "aparelho" que possa garantir a distância necessária ao desvendamento de enigmas e crimes. Esse lugar é a margem. Não estar no centro dos acontecimentos permite apreciá-los com mais independência, com maior precisão, pois “escrever é escolher, selecionar”, diz Cardoso Pires em entrevista a Fernando Assis Pacheco e, imediatamente, acrescenta: "Faz-me falta um certo distanciamento para ler o que escrevi (CARDOSO PIRES, 1982). Esse distanciamento permite, também, visualizar o perigo sem se deixar contaminar por ele, enfrentando e destruindo os seus atributos.

A escolha da margem como "posto de observação" é um outro tópico que complementa o que denominamos "o cerimonial de escrita de José Cardoso Pires". A focalização indireta e enviesada dos fatos garante ao autor o distanciamento necessário à discussão e análise com que processa a sua ficção. Trata-se da opção por um lugar marcado pelo descentramento e pela recusa à integração. Entretanto, em relação à obra de Cardoso Pires, a opção pela margem não deve ser vista apenas como um lugar de escolha. São bastante conhecidas as suas declarações acerca do lugar destinado ao escritor:

"Os escritores são sempre uma espécie de tolerados, de animais marginais que servem para dourar a festa quando é preciso, e mais nada" (CARDOSO PIRES, 1981).

"Repare, se no fascismo o escritor era um 'animal à margem', eu acho que em autêntica democracia ele deve ser 'o animal salutarmente incómodo', o homem que antevê os perigos coletivos a maior distância" (CARDOSO PIRES, 1982).

Além da identificação da responsabilidade cívica do escritor, os fragmentos acima apontam para a grande diferença entre estar à margem por opção e ser colocado à margem por não abrir mão da liberdade que todo ponto de 
vista crítico demanda. A opção pela margem revela, portanto, a liberdade de escolha de um "posto de observação" indireto que não encontra paralelo com o lugar à parte, destinado aos escritores que não aceitavam a "sintaxe de compromissos" com que o Estado Novo procurou neutralizar o discurso crítico de escritores portugueses. Mais uma vez, é importante destacar o ponto de vista lúcido com que Cardoso Pires examina as responsabilidades do escritor em face das maquinações do poder:

Em tempo: o signatário considera oportuno e significativo invocar nesta exposição o exemplo dos escritores que, nas horas difíceis da nossa história, preferiram a incomodidade de uma independência ao reconhecimento negociado de uma cidadania por tolerância ou por sujeição. Esses homens ao recusarem a sintaxe dos compromissos, procuraram acima de tudo ultrapassar a mesquinhez do tempo e cumprir o seu ofício de vanguarda, que é o de testemunhar e alertar para o futuro, qualquer que seja a perfeição do Sistema. E por isso, rejeitaram as ambigüidades transitórias e as solicitações de circunstância, certos da razão que lhes assistia e para além deles. Sem pressa. (CARDOSO PIRES, 1977a: 17)

Como primeira parte desta exposição, poderíamos entender a margem como o lugar tenso - de escolha ou de destino - de onde se pode imaginar um mundo alternativo à maciça unanimidade dos relatos estatais. A margem é, sem dúvida, um lugar possível ao exercício de alguma liberdade. Melhor dizendo, é o campo de atuação de todo escritor comprometido que se viu relegado a esse lugar incerto para o qual certos Estados impelem aqueles que não abrem mão da independência do espírito" (CARDOSO PIRES, 1977a: 16).

Nesse texto em que procuro identificar alguns dos procedimentos de escrita de Cardoso Pires, a todo instante releio a verdade tão simples e tão difícil de sua frase: "Há mil maneiras de dizer liberdade e mil maneiras de a aprender [...]” (CARDOSO PIRES, 1977c: 267).

Esse parece ter sido o mote desenvolvido em muitos dos seus textos. Eu interrompo aqui o mapeamento para iniciar a segunda parte deste texto. Trata-se de uma leitura do conto "Os caminheiros", em que pretendo discutir alguns dos procedimentos que apresentei sob o nome de procedimentos de escrita. 


\section{“Caminhar é ter falta de lugar” (CERTEAU, 1994)}

O conto "Os caminheiros", publicado pela primeira vez em 1949, integra, e de certa forma emblematiza, a coletânea de contos publicada em 1963 com o título Jogos de azar. Embora retirados de dois livros diferentes, os contos desse volume estão articulados em um núcleo comum e já evidenciam a concepção de um modelo bem definido de narrativa. O núcleo comum é constituído pela imagem emblemática do título: Jogos de azar. Como o próprio autor deixa claro - nas epígrafes e no esclarecedor prefácio "A charrua entre os corvos" (CARDOSO PIRES, 1985a: 7-12) -, o jogo de azar, por estar circunscrito aos domínios da Fortuna, é imune a todos os lances marcados pelo conhecimento ou pela perícia do jogador; o que conta é o acaso, a sorte e a Fortuna, isto é, o Azar. Apesar das particularidades de suas histórias, cada conto desenvolve, desdobra ou concentra o trágico enredo desse núcleo comum.

A concepção de um modelo bem definido de narrativa também se insinua nesses primeiros contos do autor. Trata-se de uma narrativa contida, melhor dizendo, condensada que se desenvolve a partir de pequenos incidentes cotidianos, colocados em cena para serem explorados por um processo de interrogação contínua. Nesses pequenos contos inaugurais, o narrador já não assume o confortável lugar daquele que conta uma história linear e detalhada, mas o lugar inquieto e inquietante daquele que, ao contar, interroga, perscruta e analisa. Nesse processo cambiante, o leitor, gradativamente, fica enleado e seduzido pelo clima de mistério que, logo de saída, é instalado pela estratégia da escrita interrogativa. A partir daí, somos conduzidos por desvãos, construções alusivas, fugidias, em que se percebe, claramente, que o mais importante não pode estar visível, ou melhor, que na estratégia de escrita de Cardoso Pires o mais importante nunca se conta. Esse processo de construção narrativa faz lembrar a assertiva de Ricardo Piglia: "Um conto conta sempre duas histórias" (PIGLIA, 1994).

Esse tópico, analisado por Piglia em seu $O$ laboratório do escritor, define a estrutura e natureza do conto, mais precisamente, compõe a primeira de suas teses. Com ela, o escritor argentino elabora uma teoria sobre a especificidade do conto clássico - que conta uma história, anunciando que existe outra - e a do conto moderno, que apresenta duas histórias como se fossem uma, trabalhando a tensão existente entre elas, sem nunca resolvê- 
las (PIGLIA, 1994). É essa a estrutura do conto “Os caminheiros": duas histórias, cada uma contada de maneira diferente.

Com uma linguagem enxuta, elíptica, o conto de Cardoso Pires se desenrola a partir de um episódio banal: "Os dois caminheiros seguiam ao sol no meio da estrada", em busca de um encontro.

Os dois, estrada fora, um de viola à bandoleira, o outro de casaco no braço, faziam um par solitário atravessando a tarde. Vistos de longe, lembravam dois amigos em passeio, e nunca duas pessoas que vão à vida, preocupadas com os seus assuntos. (CARDOSO PIRES, 1985b)

Nesse início de "Os caminheiros", tudo parece indicar que se trata de mais uma caminhada, um fato corriqueiro para quem caminha de um lugar a outro para sobreviver, fazendo pequenas apresentações musicais a um público incerto que pode aparecer em qualquer estrada. A vida desses caminheiros, embora sofrida, parece não ter grandes acidentes de percurso. Uma vez encontrado o público, são feitas as apresentações do cego cantor e do guia que o acompanha, e o mais é recolher as esmolas, para então seguir em busca de uma outra caminhada, outros encontros, outras "apresentações". Além disso, havia um grande entendimento entre eles:

Havia muita coisa que António Grácio compreendia pela maneira como o amigo o agarrava. A curiosidade era uma delas. Pela força dos dedos, pela demora com que os pousava ou mantinha atentos sobre o braço dele, à espera de uma oportunidade, duma explicação, podia adivinhar o cansaço, a dúvida, o desejo ou a surpresa que iam no outro. Não precisava de palavras: os dedos de Cigarra contavam-lhe tudo. (CARDOSO PIRES, 1985b: 71)

Entretanto, gradativamente, vamos percebendo que a caminhada posta em cena no conto não é uma caminhada comum. Os dois caminheiros não estão exercendo a sua atividade de "ir à vida" em busca de um público que lhes garanta a sobrevivência. Nessa caminhada, António Grácio tem um encontro marcado com um compadre. Não sabemos o sentido do encontro; o Cigarra também tenta adivinhar esse sentido, já que as imprecações de Tóino o surpreendem e, com isso, também inquietam o leitor: 
"Vida dum capado. Amaldiçoada seja ela mais aquele que a inventou". (CARDOSO PIRES, 1985b: 67)

"O que foi, Tóino?"

$[\cdots]$

"Tóino", disse o Cigarra, travando-lhe um tudo-nada o braço. "Essa conversa do teu compadre o que era?" (CARDOSO PIRES, 1985b: 71)

Esse clima de inquietação e mistério cresce a cada página, até chegar ao limite, com o encontro dos dois compadres. Trata-se de um acordo a ser feito, um acordo comercial: a venda de Cigarra por Tóino. Trata-se de uma traição, porque feita sem o conhecimento de Cigarra; ou de uma quebra de acordo, de "palavra empenhada" ao companheiro e amigo. A partir desse momento, todo o sentido de miséria trágica impregna o conto. Miguel, o comprador, examina a "mercadoria" e tenta regatear no preço:

Como quem não quer a coisa, o compadre apanhou uma folha; levou-a à boca e entretanto pôs-se a medir o Cigarra de longe.

"Não sei", disse por fim. "Duas notas é muito." E, mais alto, para o Cigarra: "Você já foi ao médico?"

$[\ldots]$

"É muito, Tóino. Duas notas é dinheiro. Depois há de ver que eu não tenho prática ...” (CARDOSO PIRES, 1985b: 79)

$[\ldots]$

"E com respeito a comida? Tem má boca? Come muito?"

"Um Pisco", respondeu Grácio. (CARDOSO PIRES, 1985b: 82)

"E a roupa?", perguntou ainda Miguel. "Eu é que pago a roupa dele?"

"Não. Nem roupa nem instrumentos, nada disso é contigo. Tu só tens de pagar a comida e receber metade dos ganhos."

"Em todo caso, Tóino. Duas notas é dinheiro. E para mais doente... Não sei, tenho de pensar."

“Tens de pensar? Mas quem é que disse que ele é doente, Miguel?” (CARDOSO PIRES, 1985b: 83) 
A crueza desse diálogo mantido entre os compadres mais se agudiza quando o confrontamos com as tímidas perguntas do cego, que, mesmo distante, consegue perceber mais esse lance do azar:

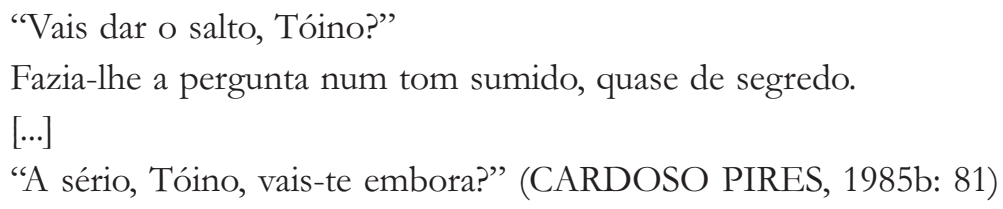

Estas perguntas sem resposta ficam ecoando, enquanto a negociação progride; ficam ecoando num silêncio resignado, enquanto um novo acordo é selado:

A questão para mim [disse Miguel] está no guia. E, como te disse, lá de guia é que eu não percebo nada."

"Aprendes, compadre. Se os cães aprendem, porque é que tu não hás de aprender?”

"É justo", concordou Miguel, com ar preocupado. "Realmente, se formos a ver bem as coisas, é fazer de cão de cego, pouco mais. Sim, como trabalho é isso. (CARDOSO PIRES, 1985b: 86-87)

Apesar da crua justeza desse último trecho, poderíamos dizer que a primeira história, ou a história de superfície desse conto, é formada por esse enredo de traição, em que a Fortuna mais uma vez é soberana na determinação da trágica caminhada. Ao longo do conto, o narrador foi evidenciando pistas que favorecem essa interpretação. A primeira pista marca-se com a presença de uma cobra que atravessa o caminho de Tóino e Cigarra. Todos sabemos que esse é um índice consagrado e de significação marcada. É natural que o leitor estabeleça a correlação entre os dois episódios. No entanto, estamos diante de uma imagem consagrada demais para não sentirmos uma certa desconfiança. Desconfiança que cresce quando conhecemos as artimanhas com que Cardoso Pires costuma tratar os signos mais evidentes, ou gastos pelo uso imposto pela tradição.

Entretanto, esse movimento de desconfiança diminui, quando um outro tipo de traição se sobrepõe ao próprio índice da traição: 
Ouviram um buzinar de automóvel e desviaram-se para a berna da estrada. António Grácio segurou o braço do companheiro: alguns metros adiante, uma cobra pardacenta lançava-se ao caminho precipitadamente.

$[\ldots]$

Estavam ambos parados. O carro passou como um sopro de fogo, a carroçaria a rebrilhar, os vidros a chisparem faúlhas de sol. À frente dele a cobra deu um salto, escapou-se numa volta, mas o condutor fez uma curva propositada e os pneus cortaram-na pelo meio. (CARDOSO PIRES, 1985b: 68)

Com esse episódio, o índice de traição como questão central do conto fica reforçado, pois essa traição humana é mais violenta porque inesperada; é mais traiçoeira porque aparece fora do lugar, como ficam fora do lugar as ações motivadas pela inconseqüência. $\mathrm{O}$ veloz motorista consegue vencer o mais escorregadio e traiçoeiro dos animais.

Ainda nessa linha de reforço ao sentido de trapaça, da traição e do engano, o escritor vai utilizar, estrategicamente, o recurso do deslocamento e fixar numa outra cena a trágica história vivida pelos dois caminheiros. A cena se compõe com a letra do fado "A tragédia desumana", recuperada por Tóino e Miguel e referida como versos de grande qualidade.

O deslocamento é um movimento interno ao relato, ou melhor, como dissemos anteriormente, há uma verdade que é dita pela voz de um outro e que, por isso, "permite fixar e tornar visível o que se quer dizer" (PIGLIA, 2001a). O deslocamento promove um movimento ficcional, "uma troca de enunciação", isto é, um movimento que põe a voz do outro no lugar de uma enunciação pessoal. Esse recurso, sem dúvida, funciona como uma espécie de comprovação, um reforço que a marca de estilo do autor parece autenticar.

Entretanto, uma das marcas que destacamos nos textos de Cardoso Pires foi o da escrita interrogativa, isto é, a estratégia de estilo que nos remete a posições diferentes, díspares; que nos leva a oscilar de um sentido a outro; a recolher pistas para depois descartá-las. Esse percurso oscilante, essa narrativa formada por desvãos nos obriga a voltar atrás, a recolher outros fragmentos para examinar, confrontar e, novamente, interrogar.

Durante a releitura do conto, alguns índices permitem acreditar na existência de uma história subterrânea que foi sendo tecida ao mesmo tempo em que a primeira, mas com uma lógica oposta. $\mathrm{O}$ desespero de Tóino durante a 
caminhada; as suas falas desencontradas das do Cigarra parecem revelar um grande segredo que o conto não deixa entrever. Isso atenua a frieza que the atribuímos de início. Além disso, depois de concretizar o "negócio", isto é, depois de vender o Cigarra ao amigo, Tóino não pode comemorar:

"Seja. O que está feito, está feito. Vamos ao copo para fechar?"

"Não posso", respondeu o António Grácio. "Fica para a próxima."

"Pago eu, caramba. Nem ao menos um copo para fechar?"

Mas o Grácio tinha pressa, agora mais do que nunca. Veio junto do Cigarra e abraçou-O:

"Desculpa... A gente não fica com razões um do outro, pois não?"

Cigarra sorriu. Fez um arabesco com a bengala e a mão tremeu-lhe. Tinha a voz do companheiro no ouvido. "O meu compadre é um gajo unhaca, verás." E também essa voz tremia.

Então quis dizer fosse o que fosse, mas só conseguiu agarrar-se ao Grácio e abraçá-lo com força, com tanta força que o peito lhe doeu como se lhe tivessem tirado todo o ar. (CARDOSO PIRES, 1985b: 87)

Como ler esse conto com esses novos argumentos? É certo que a traição (se é que podemos usar essa palavra) existe; é certo que, mesmo rasuradas, as antigas pistas ainda ficam ecoando, como um rumor que nos faz lembrar que Tóino vendeu o Cigarra por duas notas de cem escudos; que faz lembrar que o cego foi aviltado ao nível de mercadoria pelo parceiro. Mas o que também fica ecoando são as palavras do autor, que, no prefácio ao livro Jogos de azar, analisa uma charrua fora do lugar.

Para mim a charrua lançada aos corvos é um exemplo figurado da amputação do homem, um testemunho de certa destruição que se exerce, não imediatamente sobre ele, criatura física, mas sobre os instrumentos que o rodeiam, sobre os gestos e sobre as manifestações da actividade que o tornam utilizável como homem. E isso é uma outra espécie de fome, uma outra destruição. (CARDOSO PIRES, 1985a: 12)

E o que aparece, então, como estrato da segunda história é essa "espécie de fome" que devora tudo, menos a aflição, menos os sentimentos íntimos 
que o conto mal deixa entrever: há um descompasso entre falas e gestos; há um remoer de sentidos que o leitor não decifra com facilidade. Não há serenidade nesse comércio entre os compadres. Há raiva e ao mesmo tempo desespero. E, por último, apesar dos gestos contidos e da contenção das palavras, há uma espécie de tremor, de respiração interna que desmentem a objetividade ou praticidade necessárias à negociação encenada. Como ler essas fulgurações que, aos poucos, no decorrer da caminhada, vão instalarse no corpo como uma outra respiração? Como ler essa espécie de retração: o tremor das mãos, os gestos contidos, a respiração do silêncio?

Num primeiro momento, poderíamos dizer que estamos diante de histórias de "desocupados", aqueles personagens "pouco heróicos" que caminham à deriva pela vida. Situados à margem dos acontecimentos, esses caminheiros aparecem e desaparecem durante algum tempo (impossível determinar esse tempo); aparecem com suas histórias residuais que não importam muito para a economia significativa dos grandes enredos. Essa sobra e seus imperceptíveis horizontes conturbados não podem ser assimilados; são vidas obscuras, "fora de lugar" em toda parte, e por isso caminham, caminham por todos os lugares que vão dar a lugar nenhum. "Caminhar é ter falta de lugar", afirma Michel de Certeau (1994: 183). Caminhar, nesse horizonte traçado por Cardoso Pires, é, antes de tudo, dar a ver a "fraqueza e instabilidade de todas as acomodações" (BAUMAN, 1998: 15) impostas pela ordem e pelo desejo de pureza. É esta a perspectiva com que o autor analisa os enredos dos seus caminheiros:

No fundo, talvez os desocupados deste livro devam a uma situação de acaso (exterior a eles, à sua vontade) as formas de existência que lhes são impostas... Se formos a ver bem, o facto é tanto mais verdadeiro quanto é certo que o indivíduo destituído de autoridade está condenado a tropeçar a cada passo nos caprichos daqueles que a detêm como exclusivo. (CARDOSO PIRES, 1985a)

Nessa perspectiva, a noção de destino como solução interpretativa para a vida dos caminheiros fica logo descartada. O trágico percurso dos caminheiros - um cego, o Cigarra, que como o próprio nome indica é o cantor da dupla, e Tónio Grácio, moço de cego, que guia na caminhada e é responsável pela caixa de esmolas - vai ser posto em cena não como mais um tema ou uma circunstância a ser tratada pela literatura, mas como um horizonte de que é 
preciso aproximar-se com delicadeza e cuidado para poder descobrir um tipo de percepção diferente, específica; para poder captar essa espécie de rumor que nasce da ameaça e do perigo; para reconstituir os seus sentidos cifrados e chegar à verdade que os informa. Melhor dizendo, não se trata apenas de examinar os seus conteúdos, mas de buscar uma melhor percepção das forças que determinam esse universo, examinando a forma como ele é constituído e mantido à margem daquilo a que costumamos chamar realidade.

A escolha da margem em José Cardoso Pires, além de definir o seu horizonte de ação política e objeto de luta, é também uma tomada de posição, a partir da qual as relações de poder são examinadas. Como dissemos, é uma opção que define um lugar, um ponto de observação para, a partir daí, analisar a rede de poder que organiza conteúdos e que, ao organizar, classifica e valoriza, definindo o que importa ser visto e o que deve ser descartado como sobra destinada à invisibilidade cotidiana.

Nesse sentido, a "fome elementar" que o conto encena não pode ser vista como uma fatalidade, mas como um mal de que é preciso "conhecer as causas, o vírus e a sua propagação"; para despojá-lo de sua invisibilidade e falta de sentido para, enfim, como afirma o escritor, "ser unicamente objeto de resolução científica rigorosa e de estudo planificado, tal como foi a lepra, por exemplo, que se despojou de suas mitologias de Velho Testamento logo que a medicina social the vibrou o golpe adequado" (CARDOSO PIRES, 1985a: 14).

É esta a perspectiva com que Cardoso Pires constrói as suas histórias de personagens pouco heróicos, esses caminheiros que vivem

[...] abaixo de todos os sistemas morais,

Para quem nenhuma religião foi feita,

Nenhuma arte criada,

Nenhuma política destinada para eles!

$[\ldots]$

Inatingíveis por todos os progressos,

Fauna maravilhosa do fundo do mar da vida! (PESSOA, 1999: 25) 


\section{Referências Bibliográficas}

BAUMAN, Zygmunt. O mal-estar da pós-modernidade. Rio de Janeiro: Jorge Zahar, 1998.

CARDOSO PIRES, José. Entrevista à Revista DNA. Lisboa, 21 dez. 1996. . "Cardoso Pires por Cardoso Pires". Entrevista a Artur Portela. Lisboa:

Dom Quixote, 1991.

. "A charrua entre os corvos". In: Jogos de azar. 5. ed. Lisboa: O Jornal, 1985a.

. "Os caminheiros". In: Jogos de azar. 5. ed. Lisboa: O Jornal, 1985b.

. "País de espertos e todo em moral". Entrevista a Fernando de Assis Pacheco.

O Jornal, Lisboa, 3 dez. 1982.

. Entrevista a Mario Ventura. Diário de Notícias, Lisboa, 1 fev. 1981.

. E agora, José? Lisboa: Moraes, 1977a.

. "Memória descritiva". In: E agora, José? Lisboa: Moraes, 1977b.

. "Sete parágrafos sobre a liberdade e algumas inscrições murais." In: E

agora, José? Lisboa: Moraes, 1977c.

. O Delfim. Lisboa: Moraes, 1968.

CERTEAU, Michel de. A invenção do cotidiano. Petrópolis: Vozes, 1996. . A invenção do cotidiano. Artes de fazer. Petrópolis: Vozes, 1994.

FOUCAULT, Michel. Verdade e formas jurídicas. Petrópolis: Vozes, 1994.

LOURENÇO, Eduardo. "Branca eternidade”. Público. Lisboa, 27 out. 1998.

LYOTARD, Jean-François. O pós-moderno explicado às crianças. Lisboa: Dom Quixote, 1999.

PESSOA, Fernando. "Ode triunfal". In: Poemas de Álvaro de Campos. Rio de Janeiro: Nova Fronteira, 1999.

PIGLIA, Ricardo. Tres propuestas para el próximo milenio (y cinco dificultades). Buenos Aires: Fondo de Cultura Económica, 2001a.

. "Una propuesta para el nuevo milenio." Margens/Márgenes. Caderno de cultura n. 2. Belo Horizonte/Mar Del Plata/Buenos Aires, out. 2001b.

O laboratório do escritor. São Paulo: Iluminuras, 1994. 
